\title{
"Semejables a la Virgen María" La Virgen María según san Juan de Ávila en el contexto de la teología y la piedad marianas del siglo XVI
}

\author{
"Like the Virgin Mary". The Virgen Mary According \\ to Saint John of Avila in the Context of the Marian \\ Theology and Piety of the 16th Century
}

\author{
Juan Miguel Ferrer Grenesche \\ Instituto Teológico San Ildefonso de Toledo.Toledo. España \\ jmfgrenesche@gmail.com \\ ID ORCID 000-0003-0098-0769
}

\begin{abstract}
Resumen: San Juan de Ávila aúna en sus escritos sobre la Virgen María el rigor teológico y una profunda piedad mariana. La presente investigación introduce al lector en la mariología y la piedad mariana de san Juan de Âvila en el contexto de la teología y la espiritualidad del siglo XVI, que es objeto de una útil síntesis en estas páginas. Asimismo, el autor comenta la íntima relación entre María y el sacerdocio para el maestro Ávila: lo que ella realizó en la encarnación, el sacerdote lo actualiza en el altar eucarístico.
\end{abstract}

Palabras clave: Virgen María, San Juan de Ávila, teología del siglo XVI, piedad mariana, mariología

\begin{abstract}
Saint John of Avila combines theological rigor and deep Marian piety in his writings on the Virgin Mary. This research introduces the reader into the Mariology and Marian piety of Saint John of Avila in the context of 16th-century theology and spirituality. Moreover, the author comments on the intimate relationship between Mary and the priesthood for Avila: the role that she played in the incarnation is performed at the Eucharistic altar by the priest.
\end{abstract}

Keywords: Virgin Mary, Saint John of Avila, $16^{\text {th }}$-century theology, Marian piety, Mariology

* Nota del editor: El presente artículo es una reelaboración de la conferencia pronunciada por el profesor Juan Miguel Ferrer Grenesche en las jornadas de la cátedra de Mariología de la Facultad de Teología San Isidoro de Sevilla el 20 de mayo de 2021 (Sevilla). 


\section{PRESENTACIÓN}

Mi exposición va a tratar de presentar el objeto de nuestro estudio: cómo entendió san Juan de Ávila la teología y la piedad marianas. Por eso veremos primero el contexto de la teología y la piedad mariana en la época de san Juan de Ávila, donde seré más extenso. Trataré de destacar aquello que nos ayude a comprender el mundo teológico y la piedad cristiana en los que vive nuestro Santo, para poder así calibrar su enraizamiento en su tiempo, tanto como sus originalidades y aportaciones más personales. Seguidamente, sacaré unas conclusiones: primero, procurando sintetizar la posición del Santo Doctor ante el misterio de María; aquí seré muy breve evidentemente, teniendo presente que el prof. Álvaro Román presentará la mariología en los sermones de san Juan de Ávila, en otra publicación de este número de Isidorianum. Finalmente, procuraré bucear más en el alma de nuestro santo y expresar su relación, más íntima y personal, con nuestra Señora, en la que el santo maestro quería introducir también a todos sus oyentes y discípulos.

\section{TEOLOGÍA Y PIEDAD MARIANA EN LA ESPAÑA DE LA ÉPOCA DE SAN JUAN DE ÁVILA}

\subsection{Fechas en la vida de san Juan de Ávila}

La cronología de la vida de nuestro Santo coincide prácticamente con la primera mitad del siglo xvi: Nace el 6 de enero de 1499, estudia en Alcalá y Salamanca Artes y Teología y es ordenado sacerdote en 1526 tras la muerte de sus padres. Quiere dedicarse a los pobres y a la evangelización. Su propósito misionero anhelaba llegar a Méjico, pero, finalmente, su labranza será en España y singularmente en Andalucía; sin embargo, como proclama su reciente Doctorado, con irradiación al mundo entero por sus discípulos y el protagonismo de muchos de estos en los años que siguieron y en el concilio de Trento (1545-1563). San Juan de Ávila, tras una vida tan fecunda e intensa, entrega su alma el 10 de mayo de 1569.

\subsection{La teología en la España de la primera mitad de siglo XVI}

San Juan de Ávila representa uno de los grupos de teólogos españoles característicos de su tiempo, don Melquiades Andrés lo sitúa 
entre los"hombres de creación o de empresa"1 que se plantean fundar instituciones teológicas y amparar en ellas teólogos que quieran trabajar por el progreso y renovación de la ciencia divina.

En España a finales del siglo precedente y en la época de nuestro Santo, la tarea del teólogo gozaba de prestigio y reconocimiento social. Pero la teología al comenzar el siglo xv había caído en una cierta decadencia por culpa del verbalismo. Escolásticos y nominalistas discutían con gusto sobre palabras o se enzarzaban por caminos curiosos que los venían alejando de las fuentes y de la vida de la Iglesia. En las Universidades se sentía la preeminencia de las disciplinas seculares con el deseo de ocupar puestos en las esferas de gobierno de la sociedad (cf. HTE p. 582).

Pero desde la segunda mitad del siglo $\mathrm{xV}$, comienzan a florecer una serie de autores aislados, pero con una gran fuerza y decisión, van a ser los "teólogos independientes", por romper de algún modo con las escuelas existentes, y que desean favorecer un verdadero crecimiento de la teología: El Tostado, Alfonso Fernández de Madrigal (1410-1455); Juan de Segovia, importante en el concilio de Basilea (+1458); Pedro Martínez de Osma (1427-1480), profesor en Salamanca de Nebrija; y el dominico Melchor Cano (1509-1560) entre otros. Todos ellos coinciden en un ardiente deseo de "búsqueda de la verdad"; quieren una teología basada y pegada a las "fuentes"y aplicada de modo sistemático "a la vida". Gracias a ellos y al estado de pensamiento que crearon llegaremos a la que se ha llamado"edad de oro de la teología española", 1570-1620 (cf. HTE p. 583). Su repercusión en toda la Iglesia católica se debió al frescor reformista y a la solidez argumental que aportaron al concilio de Trento.

\subsubsection{Rasgos de esta teología}

Siguiendo al profesor Melquiades Andrés presentaremos como rasgos de esta teología renovada los siguientes:

a) La búsqueda de la verdad, evitando la mera curiosidad intelectual y los discursos"verbosos" (vana palabrería).

\footnotetext{
Seguiremos en todo este apartado una obra ya clásica, Melquíades ANDRÉs MARTín, “La Teología en el siglo XVI (1470-1580)”, en Melquíades Andrés MarTín (dir.), Historia de la Teología Española, vol. I: Desde sus orígenes hasta fines del siglo XVI, Madrid, Fundación Universitaria Española, 1983, 582 (579-735). En adelante esta obra será citada en el cuerpo con la abreviatura HTE.
} 
b) El retorno a las fuentes, con un gran deseo de conocer las Sagradas Escrituras y la enseñanza de los Padres de la Iglesia y los Escritores Eclesiásticos. Para esto en España jugó un papel muy importante la incorporación a la teología de los conversos procedentes del judaísmo, movimiento que se había venido favoreciendo desde tiempos de san Vicente Ferrer (1350-1419), pero que culmina en tiempos del cardenal Cisneros (1436-1517), que cuenta con muchos de estos sabios - Alfonso Zamora, Pablo Coronel, o Alfonso de Alcalá- en su obra monumental, la "Políglota Complutense", la mayor aportación cultural en la Europa de su tiempo (cf. HTE pp. 584-585).

c) La integración del humanismo con la Teología. Este rasgo tiene mucho que ver con una teología que mira a la vida, que ilumina los problemas concretos de las personas y de la sociedad. Aquí las consecuencias de la renovación fueron de una trascendencia inimaginable. A esta opción y enfoque de la labor teológica se debieron en gran medida la aportación de esta a la espiritualidad, hasta conseguir el monumento de nuestra gran escuela mística, y a la moral, incluso a la que llamaríamos primera sistematización de la doctrina social de la Iglesia con el valor de la persona en el centro del sistema y con el primer Derecho Internacional al servicio de las relaciones justas entre los pueblos y la común consecución de la paz. La conquista de Granada, el descubrir un mundo nuevo con la llegada a América, en sintonía con la sensibilidad del nuevo humanismo europeo hizo que en el humanismo hispano se desarrollara la llamada"teoría del progreso". Para nuestros pensadores, el humanismo no se puede quedar en admirar e imitar a los clásicos, se impone la necesidad de progresar, una superación continua, siempre plus ultra. Pero lejos de caer en la ensoñación de Prometeo, se sustentan en la idea del ser humano creado a "imagen y semejanza de Dios" y llamado en Cristo a ser hijos de Dios. Este deseo de progreso se encauzará por los caminos de la mística y de la moral social (cf. HTE pp. 586-592)

d) Relacionando o sintetizando todo lo anterior, esta teología será totalizante, desde la aplicación del método de "las tres vías" a la voluntad de servir en todo al ser humano y a la sociedad, a su progreso según el plan de Dios. Pero todo esto desembocó en un despertar del interés por la ciencia y la técnica, curioso es que nuestro san Juan de Ávila patentase varios inventos para subir agua (cf. HTE pp. 592-597). 
Este nuevo modo de hacer Teología fue el ambiente en que la mariología nace como disciplina, con cierto nivel de autonomía, dentro de la teología. Pero todo lo que aquí afirmamos sobre la teología en general puede aplicarse al modo de afrontar las cuestiones referentes al misterio de María en particular.

\subsubsection{Los lugares de esta teología}

Digamos ahora una palabra sobre los focos de producción y difusión de esta teología hispana: las Universidades.

a) En primer lugar hemos de citar la Universidad de Salamanca, con Francisco de Vitoria (1492-1546) a la cabeza.

Según Melquiades Andrés la Universidad salmantina adquiere un ambiente familiar, con fuerte integración de profesores y alumnos en esta época. Continúa con naturalidad la tradición medieval, pero integra decididamente las aportaciones del humanismo, consiguiendo destacar por su profundidad, modernidad y capacidad de trascendencia. Allí se favoreció, en este clima intelectual, un gradual retorno a las fuentes y una clara voluntad y convicción de poner la teología y el saber al servicio del ser humano, por medio de la búsqueda de la verdad y, más aún, de la verdad práctica. Destacan allí los profesores dominicos, pero conviviendo con agustinos, mercedarios, carmelitas descalzos y jesuitas, sin excluir a algunos miembros del clero secular. En una palabra, resume el profesor Andrés, supieron aunar felizmente la orientación que llamaba a renovar la tradición medieval, liderada por el Cardenal Cayetano (Tomás de Vio) y la corriente propiciada por el cardenal Cisneros, expresada en su prólogo a la Biblia Políglota Complutense, y por Erasmo, de hacer una Teología positiva o inductiva (cf. HTE p. 599).

Más tarde, a partir de 1560, ya casi con la muerte de san Juan de Ávila, la integración de nuevos profesores y el gradual interés por más campos de estudio, con un especial interés metafísico y psicológico, la escuela se enriquece y diversifica, hasta dar lugar a tres cauces desde su común manantial: la de san Esteban (o Bañeciana), la de los Jesuitas (Suareciana o Molinista) y la de los Agustinos, las tres consideradas "tomistas", pero la primera, más fiel seguidora de Cayetano; y las otras, más libres. Lo cierto es que sus logros fueron muy notables, como se vio en Trento, en el nacimiento de una nueva ciencia moral, del Derecho Internacional y de la sistematización del método teológico (cf. HTE p. 599). 
b) Sigue la gran y más querida obra del Cardenal Cisneros, la Universidad de Alcalá. De Alcalá beberá también, para su renovación, la célebre universidad de Coímbra, en Portugal (HTE p. 600). El énfasis bíblico positivo, el marcado humanismo, se unen en Alcalá a un decidido compromiso espiritual. Interesa renovar la vida del clero y del pueblo, se trata de favorecer la verdadera vida espiritual. De las aulas de Alcalá nace la corriente mística de los "recogidos", con una sólida apoyatura teológica, de la que careció la rama desviada de este movimiento, los llamados "alumbrados", ajenos a las aulas universitarias. En torno al 1500 la gloria de Alcalá fue unir decididamente teología y humanismo. En sus aulas estudiaron junto a san Juan de Ávila teólogos como santo Tomás de Villanueva, Francisco de Osuna, Salmerón o Laínez (cf. HTE p. 600).

c) También hemos de citar la Universidad de Valladolid, guiada por los benedictinos observantes (Congregación de Valladolid) y por los franciscanos, también de corriente reformada, del Abrojo.

d) La Universidad de Sevilla destacará por el triunfo de un humanismo antinominalista, caracterizado por Rodrigo Fernández de Santillana, o por el tomismo puro de un Diego de Deza. Pero en el ambiente sevillano lo más característico del momento fue el auge de una espiritualidad interiorizante, humanista y con ciertos sesgos de fideísmo, impulsada desde el importante monasterio jerónimo de san Isidoro.

e) Finalmente citaremos la Universidad de Valencia, que también favorece en sus aulas la fusión de teología y humanismo.

\subsubsection{Una teología para la reforma}

Toda esta renovación del pensamiento y de la espiritualidad propició en los años de los Reyes Católicos y del emperador Carlos el desenvolvimiento de dos profundas y consecutivas reformas eclesiales:

a) La primera con las órdenes religiosas como protagonistas. Franciscanos, benedictinos y agustinos serán sus principales protagonistas. El éxito de esta corriente llegará cuando los Reyes Católicos la hacen suya (singularmente Isabel) y tiene como consecuencia la renovación del episcopado español (desde 1493), nutriéndose fundamentalmente de destacados varones de estas órdenes reformadas.

No obstante, esta reforma no estuvo priva de enfrentamientos. Los dominicos consiguieron reformarse todos en 1504 y superar el inicial enfrentamiento entre "la Provincia" (los no reformados) y los 
reformados. Los franciscanos se escindieron entre "observantes" y "claustrales" a partir de 1517. Los benedictinos, por su parte, vieron nacer y separarse la rama reformista-observante, de la Congregación de Valladolid. Los Jerónimos nacen como nueva orden (1373) ya en el surco de esta corriente reformadora y llegarán a ser, de la mano de la corona de Castilla, la encarnación de este espíritu de observancia.

b) La segunda reforma nacerá del deseo de llevar a todos los bautizados este espíritu renovador y seguirá actuando entre las órdenes religiosas a las que no había llegado la primera reforma, favoreciendo en ellas el movimiento de la"descalcez", que produjo como más bello fruto a nuestros grandes místicos carmelitas.

Pero lo más característico de esta segunda reforma va a ser, como hemos señalado, hacer partícipes de este espíritu a todos los bautizados. El camino propuesto va a ser el de una oración que busca el "conocimiento de Dios", para amarle y el "conocimiento propio", para reformarse con la ayuda de Dios. El punto de encuentro en tal oración entre el conocimiento de Dios y el de uno mismo estaba en la devota contemplación de la pasión de Cristo. Fruto de este deseo de universal y espiritual reforma fue nuestra mística y una corriente muy extendida de vivir gran piedad en todos los estados de la vida cristiana, con la consecuencia también de un gran número de fundaciones para el ejercicio de las obras de misericordia y de vocaciones para la vida religiosa y el sacerdocio.

También hubo sus dificultades. Junto a muchos frutos verdaderamente eclesiales no faltaron los grupos de "alumbrados" e incluso de "protestantes", como el de Valladolid, pero más hicieron estas dos reformas por evitar la difusión del protestantismo en España y en América, que el control y el temor de la Inquisición. El profesor Melquiades Andrés concluye que compensó con creces cualquier conflictividad creada el fruto granado de afrontar sistemáticamente desde la teología y la espiritualidad católicas los problemas radicales del ser humano (cf. HTE pp. 609-610).

\subsection{La evolución de la espiritualidad y la piedad mariana en el siglo $\mathrm{XVI}$}

Ya hemos hecho varias referencias, hablando de la teología y sus escuelas, a la espiritualidad, porque algo que caracterizó el fuerte desarrollo de la espiritualidad en la España de esta época fue la 
profunda imbricación entre teología y vida que se logró y de la que ya hemos hablado.

\subsubsection{La espiritualidad}

Nos referimos ahora a algunos rasgos definitorios de la espiritualidad de este momento histórico, que coincide con la vida de san Juan de Ávila.

a) Destaca esta época por el desarrollo de la oración mental metódica. Parece que este proceso se originó entre los benedictinos de Valladolid y Montserrat, como un modo de actualizar en el contexto y sensibilidad del Renacimiento la antigua oración monástica ligada a la lectio divina, en que se forjó este nuevo modo de oración. El gran autor espiritual que se hace famoso por difundir esta nueva forma de orar es el abad de Montserrat García de Cisneros, con su "Exercitatorio de la vida espiritual" (año 1500). En él, nuestro autor pone orden y método a la práctica de la oración, al deseo de contemplación y examen/enmienda para alcanzar la unión con Dios. Junto al benedictino y dando universalidad y continuidad a esta forma de oración hay que situar a otro grande, si cabe aún más conocido e influyente: san Ignacio de Loyola con su libro de "Los Ejercicios Espirituales" (redactado en 1522 y editado en 1548). No obstante, el autor que en aquel momento más popularizó y difundió por España esta nueva manera de orar fue el padre Granada con su "Libro de oración y meditación" (aparecido en 1554). En todos estos autores y en el desarrollo general de esta práctica de oración prevaleció más la dimensión afectiva que la discusiva, especialmente en los autores de inspiración o formación cercana a los franciscanos (cf. HTE p. 656).

b) Otro rasgo, especialmente en el desarrollo de la mística, fue la llamada vía del recogimiento, cuyos rasgos más significativos serán: la búsqueda del propio conocimiento (llamada a veces de"aniquilación"), se trata de alcanzar el conocimiento de nuestro hombre viejo y su nada, para darle muerte y llegar a ser nuevas criaturas. En este sentido se ha de entender el camino de negación de san Juan de la Cruz o el desconcertante epitafio del cardenal Portocarrero en mi catedral de Toledo, pulvis, cinis, nihil. Rama espuria de esta búsqueda fue el "quietismo" desarrollado entre algunos de los alumbrados (año 1525); pero junto a esta búsqueda de la que hemos hablado no puede faltar el deseo decidido del seguimiento de Cristo, al que se llega en 
particular meditando su pasión (y tanto predicadores, como hermandades y cofradías se aplicaron a ello, marcando fuertemente la piedad popular en este sentido, solo los círculos de alumbrados toledanos se mostraron contrarios a esta predominante contemplación de la pasión de Cristo); no obstante, el punto al que hay que llegar, como cima de una vida de oración, ha de ser la transformación o unión por amor, que es don de Dios. Este será el rasgo distintivo de nuestros místicos, el mayor grado de unión con Dios se consigue por el amor, no por el conocimiento intelectual (cf. HTE pp. 657-662).

Desde la primacía del amor se desarrolló lo que se ha dado en llamar la"vía del beneficio de Dios" o del "buen amor", que recorre el camino de la belleza de la creación, singularmente la del ser humano, al amor de Dios, belleza increada; pero en san Juan de Ávila, y entre otros muchos que en esto le siguen, se realiza un paso, del amor a Dios, en general, al de Cristo, en particular, y surge así la llamada“vía del beneficio de Cristo". La encarnación es el modo escogido por Dios para granjearse nuestro amor. En este camino, el maestro Ávila llama la atención también sobre la aplicación a cada bautizado de los beneficios de la pasión de Cristo. Será a través de los desposorios de amor con Cristo como se alcance la posesión de todos sus bienes. Obrando en obediencia a Cristo ("quien me ama cumplirá mis mandatos"), el creyente hace suyos los méritos de Cristo y esto comienza por disponerse a recibir los sacramentos.

Todo este desarrollo espiritual no estaba privado de peligros, especialmente si se pierden los equilibrios que en ella caracterizan a nuestros grandes autores. Por eso no faltaron los que miraban con recelo estas vías espirituales. Así le pasó a Melchor Cano para desgracia del arzobispo toledano Bartolomé de Carranza, perseguido por sospechoso de protestantizar y estar relacionado con el brote protestante de Valladolid.

c) Finalmente, no podemos olvidar la influencia sobre nuestros espirituales del erasmismo (cf. HTE pp. 662-665), particularmente en lo que tiene de evangelismo (primacía de la meditación de los evangelios) y de paulinismo (gusto por ponerse en la escuela de san Pablo).

\subsubsection{La piedad mariana del siglo de oro}

Para terminar este apartado dedicado a la espiritualidad de la época, vamos a describir resumidamente las líneas de fuerza de la piedad 
mariana de ese momento en España. Seguiremos en esto la magistral obra del jesuita Nazario Pérez, "Historia Mariana de España". ${ }^{2}$

a) Advocaciones marianas que centran la piedad mariana de la época. Es muy posible que el influjo de los teólogos y espirituales franciscanos de la reforma favoreciese el extraordinario auge de la causa inmaculista en España. Defender la doctrina inmaculista y mirar y relacionarse con María como la Inmaculada va a ser un rasgo de la piedad mariana española de este siglo. De todos es sabido el impulso dado a estas posiciones por la reina Isabel y por el cardenal Cisneros. Precisamente Cisneros impulsó decididamente las cofradías concepcionistas por toda España y fundó en Toledo una de las primeras en 1515 , con sede en el mismo palacio arzobispal. En este contexto, santa Beatriz de Silva ve unos años antes hacerse realidad, con el apoyo de la reina y del cardenal, su nueva orden de la Inmaculada Concepción (las concepcionistas, 1484). Esta efervescencia de piedad en torno a la Inmaculada Concepción de María se plasmó en tiempos de los Reyes Católicos en abundantes obras de literatura, pintura y escultura.

Pero el auge inmaculista no significó el olvido de algunas advocaciones marianas ya consolidadas en España. Los Reyes Católicos mostraron su devoción por la Virgen del Pilar, especialmente el rey Fernando, y por laVirgen de Guadalupe, singularmente, en este caso, la reina Isabel.Y, ambos, manifestaron gran devoción por la sevillana Nuestra Señora de la Antigua, como lo manifestaron en su visita y veneración en 1477. La conquista de Granada y el descubrimiento del nuevo mundo sirvieron para acrecentar la devoción por estas advocaciones y títulos marianos y las difundieron posteriormente con profusión por América. El cardenal Cisneros también manifestó su aprecio, como la reina Isabel por la Virgen de Guadalupe, a la que encomienda, antes de zarpar, la campaña militar de Orán (cf. HME pp. 729-775).

El emperador Carlos, superada la crisis comunera, asumirá pronto las devociones de su madre la reina Juana y de sus abuelos maternos, Isabel y Fernando. En Toledo, su capital, tomó interés y consiguió que el papa Adriano vi elevase la cofradía cisneriana de la Inmaculada al rango de "archicofradía", para poder difundirla por

2 Cf. Nazario Pérez, Historia Mariana de España, vol. I, Toledo, Kadmos, 1993. Tomo aquí particularmente mis datos de la quinta parte de esta obra, titulada“María en el siglo de oro de España" (pp. 729-1049). En adelante será abreviada HME. 
todos sus reinos. No menos honró don Carlos el santuario de la Virgen de Guadalupe. Allí hizo alzar a Juan de Borgoña un grandioso retablo, que no se vería concluido hasta el reinado de su hijo, Felipe II. Singular fue la devoción del emperador por la Virgen de Montserrat, nueve veces subió a la Santa Montaña a visitarla. En Sevilla, Carlos I, como sus abuelos maternos, mostró su predilección por Nuestra Señora de la Antigua, ante la que confió su matrimonio con Isabel y de la que pidió le hiciesen una copia para llevarla siempre consigo. Esta copia parece ser que terminó depositada en el convento dominico de san Pablo y allí dio origen a la cofradía de los Esclavos de la Virgen de la Antigua.

El concilio de Trento dio ocasión a nuestros teólogos y obispos para compartir sus reflexiones y piedad inmaculistas, especialmente al tocar el Concilio la cuestión del pecado original. Destacaron en ello el cardenal Pacheco y el más posibilista don Diego de Álava, obispo de Astorga. Los Padres mayoritariamente no querían en ese contexto entrar en la definición de un nuevo dogma, no lo consideraron prudente. Pero nuestros obispos hispanos consiguieron, al menos - no fue poco-, que el modo de presentar la universalidad del pecado original y de la necesidad de la redención obrada por Jesucristo, no significase un impedimento, en el futuro, para definir la Inmaculada Concepción de María (cfr. HME pp. 821-837).

Por su parte el rey Felipe II, como los Reyes Católicos y su padre, el emperador, fue un gran devoto de la Virgen de Guadalupe y un defensor celoso de la doctrina y piedad inmaculistas. Fuera ya del periodo de la vida de san Juan de Ávila, la victoria de Lepanto (1571) favoreció mucho por toda España la devoción por el santo rosario y la difusión del culto a Nuestra Señora, bajo esta advocación del Rosario.

b) Obispos y presbiteros que destacaron por su piedad mariana en este siglo. Tras Cisneros, se debe reseñar entre los más ilustres prelados que destacaron por su piedad mariana a santo Tomás de Villanueva, a san Juan de Ribera, a santo Toribio de Mogrovejo, apóstol de América, a los cardenales Quiñones y Pacheco, grandes devotos de la Inmaculada, y, en Sevilla, a los cardenales don Alonso Manrique, don Gaspar de Zúñiga y Avellaneda y don Rodrigo de Castro, todos muy devotos de la Virgen de la Antigua. En Córdoba se significa por su piedad mariana don Juan de Toledo, dominico y de la Casa de Alba, que de Córdoba pasa a Roma, donde Pablo in lo crea cardenal y que 
luego retorna a España para ser sucesivamente ocupar las sedes de Burgos y de Santiago.

Entre los presbíteros destacará san Juan de Ávila. Entre él y sus discípulos, como indica el padre Nazario (cf. HME p. 863), abrasaron Sevilla y España de amor a la Inmaculada. En Toledo destaca don Juan Salcedo, canónigo de la Catedral, que funda (en 1502) junto a la puerta llamada "Llana" la capilla de la Inmaculada, donde será enterrado (1504); y junto a él, don Hernán Rodríguez del Barco, también canónigo de Toledo e Inquisidor, que fundará en su patria chica, El Barco de Ávila, en 1505, una preciosa capilla de la Concepción de nuestra Señora. En Sevilla destaca don Rodrigo Hernández de Santaella, que funda el colegio de Sta. María de Jesús (1505), que llegaría más tarde a adquirir el rango de Universidad. En Santiago de Compostela, el canónigo don Antonio Rodríguez, funda la capilla de la Inmaculada de esta catedral (1525). En Jaén, será el protonotario apostólico don Gutierre González Doncel (+ 1527) quien funda en la iglesia de san Andrés otra capilla de la Inmaculada. En Ávila, el deán don Cristóbal de Medina funda en su catedral la capilla de la Concepción como panteón de los deanes. Destaca el plantel de devotos de María en Cuenca, allí señalaremos a don Constancio del Castillo, canónigo, que funda el convento de la Concepción Angélica y, junto a él, pondremos a don Juan del Pozo, también canónigo, al que se debe en Cuenca la fiesta del Nombre de María. En Alcalá de Henares, fundará don Gutierre de Cetina, canónigo, el convento concepcionista de Santa Úrsula. En Palencia, encontramos a don Alonso Pérez de Silva, canónigo, que reconstruyó en Maqueda la ermita de laVirgen de los Dados. En Astorga, el canónigo don Francisco del Rincón, hizo levantar en Salas de los Barrios una iglesia dedicada a Sta. María de la Angustia (1555). En Huelva, hemos de mencionar al bachiller don Diego Márquez Ortiz, que funda nueve capellanías orientadas a la educación de los desamparados de las que una dedica a la Concepción y otra a la Soledad de Nuestra Señora; este mismo don Diego realizó importantes legados en favor de las cofradías del Rosario, la Candelaria, la Virgen de la Cinta y de la Virgen de la Antigua de Sevilla, así como tres fundaciones en el monasterio de Ntra. Sra. de la Rábida.

Pero, con todo, los más destacados clérigos de la época por su doctrina o piedad mariana fueron, junto a san Juan de Ávila, sus discípulos. Digamos algo de ellos: 
De entre los discípulos de san Juan de Ávila destacaremos, en primer lugar, a fray Luis de Granada quien llevando a las jóvenes a la devoción a la Virgen María las hacía introducirse con gozo por el camino de la pureza y el aprecio de la virginidad, de modo que muchas de sus dirigidas hacían voto de castidad, aun en la vida seglar, y otras muchas descubrieron su vocación religiosa (cf. HME p. 863).

Pero no cabe duda de que, de entre los que pueden considerarse discípulos del maestro Ávila, quien es el más conocido y que ha dejado una más fuerte estela ha sido san Ignacio de Loyola. De san Ignacio se ha llegado a decir totus quantus fuit opus Mariae fuit ("todo lo que fue e hizo fue obra de María"). Como es de sobra conocido, la conversión de Ignacio, tras su herida en campo de batalla y larga convalecencia, fue todo un proceso donde él reconoce haber sido curado tanto interna como externamente, un proceso guiado por Dios en el que san Ignacio aprende, además, el arte del discernimiento y del acompañamiento a las personas. Pero en ese proceso san Ignacio también reconoce el papel eminente de la Virgen María. Durante su convalecencia, en cuanto pudo caminar, peregrinaba cada día desde Azpeitia a Ntra. Sra. de Olaz para rezar allí la Salve. María se le había aparecido, con su divino Hijo en brazos, durante su postración y este signo de ternura de Dios y de María quedó grabado en el alma de Ignacio. Curado, peregrina agradecido al santuario de Aránzazu; allí hizo voto de castidad; más tarde peregrinó hasta Montserrat; allí vistió sayal y se encaminó a Manresa (año 1522), que era conocida como la "Ciudad de la Virgen". En ella redactó el libro de los Ejercicios, fruto de toda su acumulada experiencia espiritual (cf. HME p. 868). Ya estudiante en París, cuando inicia con sus primeros compañeros la Compañía de Jesús, elige el día de la Asunción para realizar con ellos en Montmartre los primeros votos. Cuando el grupo naciente peregrina a Roma y busca la aprobación de la Iglesia, confiesa que María y Jesús son su consuelo en las tribulaciones y con ellos se encuentra en la capillita de la Storta. Ordenado sacerdote en Roma, san Ignacio celebrará su primera misa en Sta. María la Mayor y recién nacida la Compañía la pondrá bajo la protección de la Virgen romana de la Strada ("el Camino"), capillita hoy dentro de la iglesia romana de il Gesù.

San Ignacio consideró toda su vida como guiada por María. Cosida al pecho llevaba una imagen de la Dolorosa y en el pomo de su bastón llevaba una imagen de la Inmaculada. Aprendiendo del 
fundador, los primeros jesuitas ${ }^{3}$ decían: sim marianus ut sim jesuita. No se concebía un jesuita sin devoción a la Virgen María. Se comprende como san Ignacio admirase a san Juan de Ávila y desease verlo en la compañía de Jesús, al conocerlo y tratarlo, habían emergido los lazos entre dos almas, en muchas cosas, gemelas (cf. HME pp 868-873).

c) Entre los religiosos de diversas órdenes, además de los ya enumerados por su vinculación con san Juan de Ávila, citaremos a san Juan de la Cruz y santa Teresa de Jesús, figuras señeras de la gran escuela mística española de los carmelitas, que también destacaron por su piedad mariana. Ellos pertenecían a una orden "de María", como lo es la del Carmen. Pero también hemos de reseñar a algunos exponentes de la gran orden de la reforma en España, los Jerónimos. Así fray Hernando de Talavera (1428-1507), confesor de la reina Isabel y primer arzobispo de Granada, o fray Gabriel de Talavera (1545-1621), uno de los más brillantes priores del monasterio de Guadalupe. De entre los agustinos ya citamos como arzobispo de Valencia al gran predicador y limosnero santo Tomás deVillanueva; pero, con relación a la Mariología y la piedad mariana, descuella san Alonso de Orozco (1500-1591). Entre los dominicos destacan en este periodo san Luis Beltrán (1526-1581), el gran teólogo Melchor Cano (1509-1560) y el ya citado arzobispo de Toledo, Bartolomé de Carranza.

Muy importantes en la difusión entre el pueblo sencillo de la piedad mariana, con sus nuevas formas, y del inmaculismo, fueron los franciscanos. Destacaré a fray Juan de Guadalupe, a san Pedro de Alcántara (1499-1562), san Salvador de Horta (1520-1567), gran taumaturgo que con un ave María hacía milagros. Popular en España e Italia fue el beato Pedro Nicolás Factor (1520-1583), pintor y místico; san Pascual Baylon (1540-1592), apóstol de la Eucaristía, y tierno hijo de María, y san Francisco Solano (1549-1610), el místico del Magnificat.

\subsubsection{El calendario mariano de la época}

Será el italiano afincado en España, don Pedro Mártir de Anglería (1457-1526), que llegó a ser embajador de España en Egipto y cronista

3 De entre estos primeros jesuitas destacan en su piedad mariana, entre otros, san Francisco Javier, los grandes teólogos en Trento Laínez y Salmerón, el padre Nadal o el gran predicador padre Martín Gutiérrez. Todos ellos decididamente inmaculistas, tanto en teología como en piedad mariana (cf. HME pp. 870-873). 
del nuevo mundo, el que en su testamento nos ofrece el elenco de las fiestas marianas del calendario litúrgico entonces vigente en las diócesis españolas. Reproducimos por su interés dicho elenco:

- La Concepción de Nuestra Señora;

- su Natividad;

- la Presentación en el Templo (a los tres años de edad o, también llamada, fiesta de la Virgen Niña);

- la antiquísima en la tradición hispana de Santa María de la "O" (continuidad de la Expectación del Parto, o Anunciación romana);

- la de la Purificación;

- la de la Transfixión ("una espada te traspasará el alma");

- la Anunciación;

- la de la Visitación;

- la de las Nieves (ligada al origen de Santa María la Mayor de Roma y a la exaltación de la Divina Maternidad);

- y la de la Asunción.

En 1530 se pidió a Roma poder celebrar también una fiesta de los Desposorios, mas no fue autorizada.

Nuestra idea sobre la piedad mariana en la España del llamado "siglo de oro" puede verse complementada con los datos sobre los hallazgos de imágenes de María, los milagros marianos reconocidos y las gracias extraordinarias concedidas por la Santa Sede en este periodo a España. Tomamos estos datos de la HME del padre Nazario y los ofrecemos en nota. ${ }^{4}$

4 a) Hallazgos de imágenes marianas: "Virgen de la Cruz" en Escalona de Segovia; "Virgen del Monte Santo" (1521) en Villarluengo de Aragón; "Virgen de Guadalupe" de Fuenterrabía (1526); "Virgen de la Cueva Santa" en Segorbe (1504); atestiguada en 1553: "Virgen de las Angustias" de Granada (1545-1553), llevada a Granada por dos mozárabes toledanos o, según las tradiciones, por dos santos del cielo o ángeles; "Virgen de Villaviciosa" en Córdoba (1528); el traslado del santuario de la "Virgen de la Misericordia" en Borja (1540); la "Virgen de la Coronada" en Jaén (1515); el renacer del culto en el santuario de la"Virgen de la Consolación" con la llegada a Utrera de los Carmelitas Descalzos (1557), en 1558, el ermitaño Juan restauró la ermita y colocó en ella la imagen.

b) Milagros: en Guadalupe, entre 1566 y 1599 se reconocen 29 milagros; en 1513 se produce en Vitoria, durante una procesión del Rosario, el milagro "de la cera"; en 1516 en Mondragón el día de la Natividad un terrible incendio amenazaba destruir la villa, los devotos sacaron la imagen de Ntra. Sra. del Rosario y el incendio se detuvo; en 1520, en Concentina (Alicante) una imagen de la Inmaculada regalada por Nicolás v (papa de 1447 a 1455) a don Jimeno Pérez, conde de Concentina, por los servicios prestados, manó sangre y comenzó a 


\section{CONCLUSIÓN: SAN JUAN DE ÁVILA Y LA VIRGEN MARÍA}

\subsection{San Juan de Ávila ante el misterio de María}

El teólogo riojano, don Pedro Jesús Lasanta, en su "Diccionario Teológico-Espiritual de san Juan de Ávila" dirá, como introducción a la voz"María":

San Juan de Ávila destacó la santidad de María, obediente siempre al querer de Dios, que le llevó al extremo de ofrecerse junto a su Hijo al pie de la cruz, para que los hombres alcanzáramos el perdón de Dios. Tanto sufrió en el Calvario que, en verdad, es la reina de los mártires.

ser llamada "Virgen del Milagro" (allí mismo un informe en forma de atestado de 1590 habla de una imagen de la Virgen que lloró, no se sabe si se trata de la misma); en 1526 en Tobed la"Virgen de Tobed" (pintada en 1359-1362, hoy en el Museo del Prado) sudó una substancia oleaginosa y el rey Felipe II mandó realizar un informe oficial consultando a los testigos; en 1542 en Mallorca, en Porta Pí, un marinero enfadado lanzó una bola de metal (petanca) contra la imagen de la Virgen que presidía la portada del Hospital de niños huérfanos ("Virgen del Portal"), esta al punto manó sangre; desde entonces se la conoce como la "Virgen del Milagro" y fue trasladada al interior del edificio, a la capilla; en 1544 la"Virgen del Jardín"o "del Rosario"se hizo famosa por cegar con luz a los piratas musulmanes que pretendían saquear su ciudad de Gandía.

c) Gracias concedidas por la Santa Sede, relacionadas con el culto mariano: en 1507 Julio II concede un jubileo para la Virgen de la Antigua de Sevilla; en 1509 se concede misa y oficio propios para celebrar con rango de fiesta a la Virgen de la Cinta, de Tortosa; los papas León x (papa entre 1513 y 1521) y Clemente VII (papa entre 1523 y 1534) concedieron sucesivamente diversas indulgencias en favor de Ntra. Sra. de la Piedad de Baza; en 1518 León x también agració con especiales indulgencias el santuario de laVirgen del Campo de las Caramillas, en Caramillas (Teruel); Clemente vil, por su parte, concedió el título de basílica menor al santuario de Sta. María del Cluniaco (Coruniego o Cruñego) en Villafranca del Bierzo (León) sobre el Camino de Santiago; por su parte, el antiguo preceptor del príncipe Carlos (luego emperador Carlos v), Adriano de Utrech, siendo en ausencia de don Carlos (mientras Este se ocupaba de su designación como Emperador) Regente de los reinos de España, fue elegido papa y tomó el nombre de Adriano vi y, como papa, confirmó y actualizó las indulgencias que sus predecesores habían concedido al santuario de Ntra. Sra. del Pilar de Zaragoza; indulgencias singulares que siguieron concediendo, más tarde, Clemente VII en 1527 y Pablo III (papa entre 1534 y 1549): este mismo Pablo concederá también una singular indulgencia en favor de santuario de Ntra. Sra. del Puy en Estella (Navarra). Cf. HME p. 948. 
Ella es la Inmaculada, Madre de Dios, pues de ella nació Jesucristo, el Hijo del Altísimo, vencedor del pecado y de la muerte, que realizó la obra de nuestra redención, tal como le encomendara el Padre. Jamás conoció la esclavitud del pecado, ni siquiera la más pequeña falta o imperfección. Es la toda santa, llena de gracia y de amor de Dios, más que todos los ángeles y santos juntos... Es ejemplo de humildad para nosotros.

Asunta en el cielo, intercede constantemente por nosotros, sus hijos, a fin de que, viviendo una vida santa, alcancemos también la gloria celeste. Es nuestra Medianera en Cristo, Medianera universal de la gracia. ¡Cuánto agradecimiento y amor debemos a María, sus hijos cristianos! Ella nos dio al Salvador, e intercede constantemente en favor nuestro. Todos los bienes nos vienen por las manos de María, siempre íntimamente unida a su divino Hijo ¡Cómo habremos, pues, de amarla e imitarla! ${ }^{5}$

De esta condensada exposición se puede deducir que san Juan de Ávila en su pensamiento mariológico tenía presente los dogmas marianos ya definidos en su tiempo - Maternidad divina y perpetua Virginidad - y a su vez asumía las doctrinas teológicas que llevaría a las futuras definiciones de la Inmaculada Concepción y la Asunción en cuerpo y alma al cielo, no menos que otras enseñanzas teológicas sobre la Corredención (sin usar todavía el término) y la de la Mediación Universal de las gracias merecidas por Cristo en nuestro favor. Pero, al mismo tiempo, se ve que sus propuestas teológicas no son puras elucubraciones, por metodológicamente asentadas que pudiesen ser, sino fruto de un estudio lleno de piedad, y de una piedad alimentada por la inteligencia de los misterios. Cuando san Juan de Ávila habla de los misterios de Cristo, o aquí de María, habla con rigor de teólogo, aún bebiendo no solo de los libros o fuentes, sino también de su vida espiritual.Y, al mismo tiempo, esto le ayuda en el plano discursivo a presentar los datos de la fe con piedad y así suscitar en lectores u oyentes de su doctrina el deseo de compartir ellos también esta forma de conocer, imitar-seguir y amar.

En el más elaborado "Diccionario de san Juan de Ávila", preparado por mons. Juan Esquerda Bifet, ${ }^{6}$ además de la voz"María", encontramos las referencias a la "Anunciación" (pp. 67-68); la "Asunción" (pp. 76-79); el "Corazón de María" (pp. 236-238); la “Dolorosa" (pp.

5 Cf. Pedro Jesús Lasanta (cur.), "María”, en Diccionario Teológico-Espiritual de san Juan de Ávila, Madrid, Edibesa, 2012, 249 (249-256), los subrayados son míos.

6 Cf. Juan Esquerda Bifet, Diccionario de san Juan de Ávila, Burgos, Monte Carmelo, 1999. 
310-313); la "Inmaculada" (p. 509); la "virginidad" (pp. 944-945), donde habla de la virginidad como vocación cristiana, pero presenta a María como Virgen de vírgenes; la "Espiritualidad mariana" (pp. 375-379); y el“Magníficat” (pp. 584-585).

Don Juan Esquerda desglosa la voz"María-Mariología" en los siguientes apartados: 1) Doctrina y espiritualidad mariana de san Juan de Ávila; 2) Madre de Dios y asociada al Redentor; 3) La Virgen; 4) María, nuestra Madre y Medianera; 5) María, toda santa, obra maestra del Espíritu Santo; 6) Devoción, espiritualidad y culto. A su vez en la voz"Espiritualidad Mariana"trata de: 1) Naturaleza de la espiritualidad y devoción mariana; 2) Los ejemplos y la doctrina del Maestro Ávila; y 3) Características de la espiritualidad mariana.

Puede apreciarse por las voces citadas que, a la hora de tocar los dogmas o las doctrinas teológicas sobre el misterio de María, san Juan de Ávila lo hace, no tanto confeccionando un tratado, cuanto predicando las fiestas del calendario litúrgico de su tiempo, como hemos tenido ocasión ya de presentarlo anteriormente. El Santo aparece aquí como predicador. En otro artículo de este número, el prof. Álvaro Román desarrollará el contenido teológico de los"sermones". Yo aquí solo señalo cómo este contexto favoreció la impostación de su mariología, que no sigue tanto un esquema simplemente didáctico, sino que une ciencia y vida del predicador; y busca no solo la exposición completa y veraz de la enseñanza, sino también abrir a sus oyentes a su mismo camino vital, para que alcancen su mismo saboreo y beneficio de los misterios.

También se puede observar, siguiendo estas voces aquí enumeradas, que las enseñanzas mariológicas de san Juan de Ávila en sus tratados, singularmente en el Audi filia, van a dar como resultado, como bien muestra don Juan Esquerda en la voz"Espiritualidad Mariana", que san Juan de Ávila introduce a María en nuestra relación con la Trinidad, cómo esta lo hizo en la historia de salvación. Muy importante es por eso en la enseñanza de Ávila sobre María la acción que atribuye al Espíritu Santo. Por el Espíritu, María pudo cumplir su papel en el misterio de la encarnación, nacimiento y vida oculta de Jesús, pero también por él puede realizar cada día la misión que su Hijo la encomendó frente a su Iglesia y para con los discípulos de cada época. Por otro lado, al pretender presentar a María como modelo de vida para los cristianos, resulta interesante en la mariología o espiritualidad mariana del Santo, cómo cobra importancia la 
persona de María y su desarrollo humano y sobrenatural a lo largo de su peregrinación terrena — su vida concreta y sus virtudes ejercidas en ella—, lo que da a la mariología del maestro Ávila gran actualidad e interés.

\subsection{María presentada por san Juan de Ávila}

Cuando la diócesis de Córdoba celebraba el "año jubilar" por el doctorado eclesial de san Juan de Ávila y, dentro del mismo, el magno congreso, "San Juan de Ávila, Doctor de la Iglesia" (Córdoba 25-28 abril 2013), vio la luz el precioso volumen de las actas de dicho congreso, una más de las recientes grandes aportaciones al conocimiento de la figura humana y de santidad del que fuera conocido, ya en su tiempo, como "Maestro Ávila". ${ }^{7}$ Pero sorprende que ninguna de las ponencias de dicho congreso afrontase, particularmente, la mariología y piedad mariana de nuestro Santo. Este artículo trata de fortalecer el conocimiento de esta faceta de la vida y pensamiento del Santo Doctor.

El gran autor espiritual y mariólogo, mons. Esquerda Bifet, aparte de la estupenda síntesis que ya había ofrecido en su "Diccionario de san Juan de Ávila", ofreció en las "Semanas Mariológicas Españolas" de 2014 y 2016 dos muy completas aproximaciones a esta importante faceta de la vida y enseñanza del maestro Ávila. ${ }^{8}$

En la primera de ellas, titulada"La Virgen Dolorosa, Madre de la Esperanza, en san Juan de Ávila", don Juan, tras situar la devoción a María en el contexto de la importancia de la contemplación de la pasión de Cristo en la teología y espiritualidad del tiempo de nuestro Santo, desarrolla la perspectiva de la esperanza cristiana en la escuela de la Virgen María, insertada plenamente en el misterio pascual de Cristo. Así lo va presentando en los apartados del dos al cuatro de su ponencia, bajo los expresivos títulos de: 2) “Una espera dolorosa alentada por el amor" (pp. 117-121); 3) "Una espera confiada iluminada por la fe en Cristo resucitado" (pp. 121-124); y 4) "Una espera compartida en la caridad fraterna y la misión" (pp. 124-128). De este

7 Cf. Juan Aranda Doncel - Antonio Llamas Vela (eds.), San Juan de Ávila, Doctor de la Iglesia, Actas del Congreso Internacional, Córdoba, Diputación de Córdoba, 2013.

8 Cf. Juan Esquerda BifET, “LaVirgen Dolorosa, Madre de la Esperanza, en san Juan de Ávila", Estudios Marianos 81 (2015) 113-130; e ID.,"María, Madre de misericordia, en san Juan de Ávila", Estudios Marianos 83 (2017) 293-328. 
modo traza un retrato espiritual de san Juan de Ávila, santo cuya vida se articula en la vivencia ejemplar de la esperanza, la fe y la caridad, como toda santidad cristiana auténtica, y lo hace mostrando la implicación de la"maternidad/intercesión de María" en todo ello.

En la segunda, con una ponencia bajo el título de"María, Madre de misericordia, en san Juan de Ávila", el prof. Esquerda Bifet sitúa primero la categoría teológica de la misericordia, entroncándola con Dios amor y viendo su inserción en la vida e historia de los seres humanos, a través del misterio de la encarnación del Verbo. Así pasa a continuación a presentar, de la mano del maestro Ávila, el papel dado por Dios a María en esta dispensación del amor misericordioso. Lo hace en dos apartados de su ponencia, el tercero y el cuarto, titulados respectivamente: $\left.3^{\circ}\right)^{\prime \prime}$ La misericordia en relación con la maternidad espiritual de María" (pp. 305-311); y 4) "María, Madre de misericordia" (pp. 312-319). De este modo don Juan nos presenta el papel de María en la vida y enseñanza de san Juan de Ávila en relación con dos elementos definitorios del pensamiento del maestro Ávila, inserto en las corrientes teológicas y espirituales de su tiempo y con sus personales desarrollos: la centralidad del amor y la doctrina del beneficio de Cristo.

Estos dos artículos de don Juan Esquerda, ambos tras el congreso de Córdoba y la publicación de sus actas, sin pretender darnos una visión completa de la dimensión mariana de la doctrina y vida de san Juan de Ávila, sí que nos obligan a reconocer lo importante de esta dimensión mariológico/mariana para obtener una percepción completa de la personalidad apostólica, espiritual y teológica del maestro Ávila.

No me toca a mí trazar la visión completa del misterio de María en la enseñanza de san Juan de Ávila, pero no puedo cerrar este apartado de presentación de las aportaciones de Esquerda Bifet al pensamiento y figura de nuestro Santo sin hacer referencia a las conclusiones de los dos artículos citados. En las del primero, don Juan resume:"una espera permanente con María, en la Iglesia de todos los tiempos" (pp. 128-130). En el segundo, propone un apartado $5^{\circ}$ que reza: "la espiritualidad mariana del sacerdote y de todo apóstol en relación con su actitud ministerial de misericordia" (pp. 319-325).Y el autor en estos apartados no hace otra cosa que lo que hace san Juan de Ávila: que vive para compartir el don recibido y enseña para abrir mente y corazón a este compartir. La teología y la espiritualidad son para ayudar a comprender y dejarse introducir en una vida nueva.Y, 
así entendidas vida y enseñanza, estas se hacen constructoras de comunión y fuerza para la misión. Alumbran comunión y misión, cristianos que son discípulos misioneros. Se revela así la sorprendente actualidad del pensamiento y del estilo de san Juan de Ávila.

Pero no puedo cerrar este apartado de mi exposición sin sacar de los artículos de don Juan Esquerda unos rasgos de la mariología y piedad mariana del maestro Ávila:

- Su vida y su doctrina, también en lo mariológico-mariano, beben de los evangelios y las cartas de san Pablo (aquí particularmente de los evangelios).

- Todo lo relativo a María está en él firmemente imbricado en el misterio de Cristo y de la Iglesia. Manando del designio del Padre, realizado por el Espíritu Santo en la historia, hasta su consumación.

- Mariología y piedad mariana, dentro de la teología y espiritualidad católicas, tienen que insertarse y ponerse al servicio del proyecto de Dios, se ordenan al bien, a la santidad, de cada ser humano y de la entera humanidad. Son para la misión de cada fiel y de la Iglesia. Son para construir la Iglesia y llegar a llevarla a su consumación, siempre en docilidad al Espíritu santo.

\section{3. "Semejables a la Virgen María". Compartiendo su vivencia mariana con sus hermanos sacerdotes}

Coinciden cuantos se acercan a la obra de san Juan de Ávila que nuestro santo doctor comprende que todos los bautizados estamos llamados por Dios a la santidad, a la identificación con Cristo. A dar esto a conocer dedicó gran parte de su predicación y de sus escritos, singularmente su Audi filia. Pero también es sentencia común que "la niña de sus ojos" eran sus hermanos presbíteros. Su formación integral y eclesial - por aquel entonces tan deficitaria en muchos lugares-, su verdadera consagración al servicio de dar vida a todos, de plantar y hacer crecer la Iglesia. Por eso gran parte de sus predicaciones y cartas se dirigen singularmente a los sacerdotes y para ellos y en favor de su recta formación sus fundaciones de Colegios y Universidades.

En este contexto, para él, el centro de la formación es la oración, que excita el amor y lleva, siguiendo al Amado, a una cada vez mayor identificación con él de mente y corazón. Ahora bien, este no es un proceso puramente intelectual y menos aún partidista, segregador, 
que hiciese al sacerdote vivir ausente de los demás. El verdadero proceso de escucha, oración y seguimiento, lo que hace es aunar; aunar con los de cerca y los de lejos.

En su predicación y en sus escritos sacerdotales, san Juan de Ávila comparte esencialmente su relación con Cristo sacerdote, con la Iglesia y su Misión y también, cómo no, su trato y contemplación de la Virgen. Lo que él estudia, reza y vive lo comparte con sus hermanos sacerdotes. No es una simple opción preferencial de tipo teórico. Para él es una pulsión espiritual, que arranca del corazón de la Trinidad, que entra en el mundo por la encarnación del Verbo y se manifiesta en todas sus obras, en todos sus misterios y que llega hasta nosotros gracias al obrar de la Iglesia, siempre asistida por el Espíritu Santo. Y ligada a estos pasos — "encarnación del Verbo", "Espíritu Santo", "Iglesia" — es como san Juan de Ávila nos presenta a la Virgen Inmaculada Madre de Dios y nuestra.

No es el erudito que presenta a María como un objeto de su investigación, con todo lujo de detalles, pero con distancia y frialdad. No es el sentimental que comparte emociones ciegas y empalaga con encomios que más ocultan que muestra a nuestra Señora. Se trata del hijo y condiscípulo, para él es su madre, con él es discípula de Cristo y todo a una, ella todo se lo enseña y le ayuda, como madre, a conseguir lo que con ella ha deseado.

Este modo de entender la mariología y la piedad mariana se refleja muy bellamente en la página que nos ofrece la Liturgia de las Horas en el Oficio de Lectura de la memoria de san Juan de Ávila dentro de los propios para España. Se trata de la segunda lectura de esta hora, tomada de una plática escrita por nuestro Santo para ser leída a los participantes en el Sínodo cordobés de 1563. Reproducimos algunos fragmentos que luego comentaremos:

Mirémonos, padres, de pies a cabeza, ánima y cuerpo, y vernos hemos hecho semejables a la sacratísima Virgen María, que con sus palabras trajo a Dios a su vientre [...]Y el sacerdote le trae con las palabras de la consagración, y no lo trajeron los otros lugares, sacando a la Virgen. Relicarios somos de Dios, casa de Dios y, a modo de decir, criadores de Dios; a los cuales nombre conviene gran santidad. ${ }^{9}$

9 Conferencia Episcopal Española, Liturgia de las Horas, vol ir: Tiempo de Cuaresma, Santo Triduo Pascual, Tiempo Pascual. Reimpresión actualizada, Madrid, Libros litúrgicos, 2012, 1515-1516. 
En este texto concreto san Juan de Ávila compara la respuesta de María al mensajero divino con el sacerdote que pronuncia la consagración, celebrando la Santa Misa. María y el sacerdote hacen así presente al verbo encarnado en el mundo, ella por la encarnación, nosotros por la eucaristía. Pero para que esto la sirviera para convertirse en verdadera madre de Dios, ella hubo de entregarse plenamente a Dios y a su proyecto, tuvo que hacerse discípula e hija de su Hijo. Del mismo modo para que el sacerdote pueda santificarse en el ejercicio de su ministerio, singularmente celebrando la eucaristía, hace falta que por la palabra que pronuncia, antes se consagre él que el pan, que esté dispuesto a cumplir con la voluntad de Dios. Resuenan de fondo las palabras de Jesús: "Mi madre y mis hermanos son estos: los que escuchan la palabra de Dios y la cumplen" (Lc 8,21). Pero ese cumplimiento de la Palabra de Dios es inseparable de la aceptación del designio divino sobre la propia vida, la santidad. Del mismo modo que la vocación de María explica todo en orden a cómo Dios la prepara para su misión. Así también para nosotros Dios con la llamada a la misión nos ofrece una preparación, pero la tenemos que asumir libremente, paso a paso, es esta apropiación de la obra de Dios en nosotros contamos con la ayuda de la que nos precede, la Virgen María. Ella nos ayuda a pasar de lo sacramental a lo existencial a hacernos una cosa con Cristo sacerdote-víctima. La verdadera devoción a María es asociarnos a su"sí", en el despliegue de nuestra vida entera, de modo que nos veamos un día asociados al elogio que el propio Hijo hizo de su madre: "Mejor, bienaventurados los que escuchan la Palabra de Dios y la cumplen" (Lc 11, 28). Es decir, bienaventurados los "semejables a la Virgen María". 


\section{BIBLIOGRAFÍA}

Andrés Martín, Melquíades, “La Teología en el siglo XVI (14701580)", en Melquíades Andrés Martín (dir.), Historia de la Teología Española, vol. I: Desde sus orígenes hasta fines del siglo XVI, Madrid, Fundación Universitaria Española, 1983, 579-735.

Aranda Doncel, Juan - Antonio Llamas Vela (eds.), San Juan de Ávila, Doctor de la Iglesia, Actas del Congreso Internacional, Córdoba, Diputación de Córdoba, 2013.

Conferencia Episcopal Española, Liturgia de las Horas, vol II: Tiempo de Cuaresma, Santo Triduo Pascual, Tiempo Pascual. Reimpresión actualizada, Madrid, Libros litúrgicos, 2012.

EsQUeRDA BifET, Juan,“LaVirgen Dolorosa, Madre de la Esperanza, en san Juan de Ávila", Estudios Marianos 81 (2015) 113-130.

Esquerda BifET, Juan, "María, Madre de misericordia, en san Juan de Ávila", Estudios Marianos 83 (2017) 293-328.

Esquerda Bifet, Juan, Diccionario de san Juan de Ávila, Burgos, Monte Carmelo, 1999.

Lasanta, Pedro Jesús (cur.), "María", en Diccionario TeológicoEspiritual de san Juan de Ávila, Madrid, Edibesa, 2012, 249-256.

Pérez, Nazario, Historia Mariana de España, vol. I, Toledo, Kadmos, 1993. 